\title{
Black Silicon Solar Cells Modeling and Model Parameters Estimation
}

\author{
Yongtao $\mathrm{Li}^{1,3}$, a , Heng Kang ${ }^{1,2}$, Luojun Huang ${ }^{1,2}$, \\ Yupeng Jin ${ }^{1}$, Xiaomeng Sun ${ }^{1,3}$, Yang Xia ${ }^{1,3}$
}

${ }^{1}$ Key Laboratory of Microelectronics Devices \& Integrated Technology, Institute of Microelectronics, Chinese Academy of Sciences, Beijing 100029, China

${ }^{2}$ University of Chinese Academy of Sciences, 100029, Beijing, China

${ }^{3}$ Beijing Key Laboratory of IC Test Technology, 100088, Beijing, China

aliyongtao@ime.ac.cn

Keywords: black silicon; modeling; model parameters; estimation.

Abstract. For the purpose of predict the electrical characteristics of black silicon solar cells, a simple lumped-parameter equivalent circuit model is proposed. This model is in the form of electrical equivalent circuit which contains one diode, one current source and two resistances. The model contains linear and nonlinear components. A method based on some simplifications and approximation to the nonlinear function has been proposed to estimate the model parameters. To verify the model and the method, two kinds of black silicon solar cells were used to measure the I-V curves and P-V curves at various irradiance conditions. Simulations and experiments have been conducted to confirm the operation of the proposed model and estimation method.

\section{Introduction}

Photovoltaic (PV) cells which convert sunlight into electrical energy have become a promising renewable energy to solve energy crisis and environmental problems. For a rapid and reliable PV system design, an efficient, fast and accurate model is indispensable. Many models have been proposed in resent years [1-6]. Obviously, different model have different accuracy and computational complexity. This is a trade-off between those two issues. Due to its high efficiency of energy convert, black silicon solar cells have been widely studied in the photovoltaic field [7-9]. However, there are few papers focus on model of black silicon solar cell .

In the present study, a simple model for the black silicon PV cell which is an equivalent circuit with a single diode is used. Based on the model, the model parameters are extracted from the datasheets by using a series of simplifications and approximations. The modeling and parameters estimation method will be investigated in detail.

\section{Modeling and parameters estimation}

The electrical equivalent circuit module of black silicon solar cell is depicted in Fig. 1, which contains a photocurrent source, a p-n junction diode, a p-n junction capacitance, a series resistor and a shunt resistor. Due to the p-n junction capacitance is relatively small, and the time constant of the PV system is large enough, the influence of the p-n junction capacitance can be ignored. Applying Kirchhoff's current law (KCL) and Shockley equation to the junction point of these two resistors gives the characteristic equation of the solar cell, which is a nonlinear transcendental equation, as follows:

$$
I=I p h-I_{0}\left\{\exp \left[\frac{q(U+I R s)}{A K T c}\right]-1\right\}-\frac{U+I R s}{R s h}
$$


Where $U$ and $I$ are respectively the output voltage and current of the solar cell, Iph is the photocurrent which is proportional to the irradiance [10]; $I_{0}$ is the diode saturation current, $R_{S}$ is the series resistance, $R_{s h}$ is the parallel resistance, $\mathrm{A}$ is the ideality factor of the diode which change with the output voltage, $K$ is the boltzmann constant $\left(1.38 \times 10^{-23} \mathrm{~J} / \mathrm{K}\right)$ and $T_{c}$ is the absolute temperature. Hence, this model needs five parameters: $\left\{I_{p h}, I_{0}, A, R_{s}, R_{s h}\right\}$.

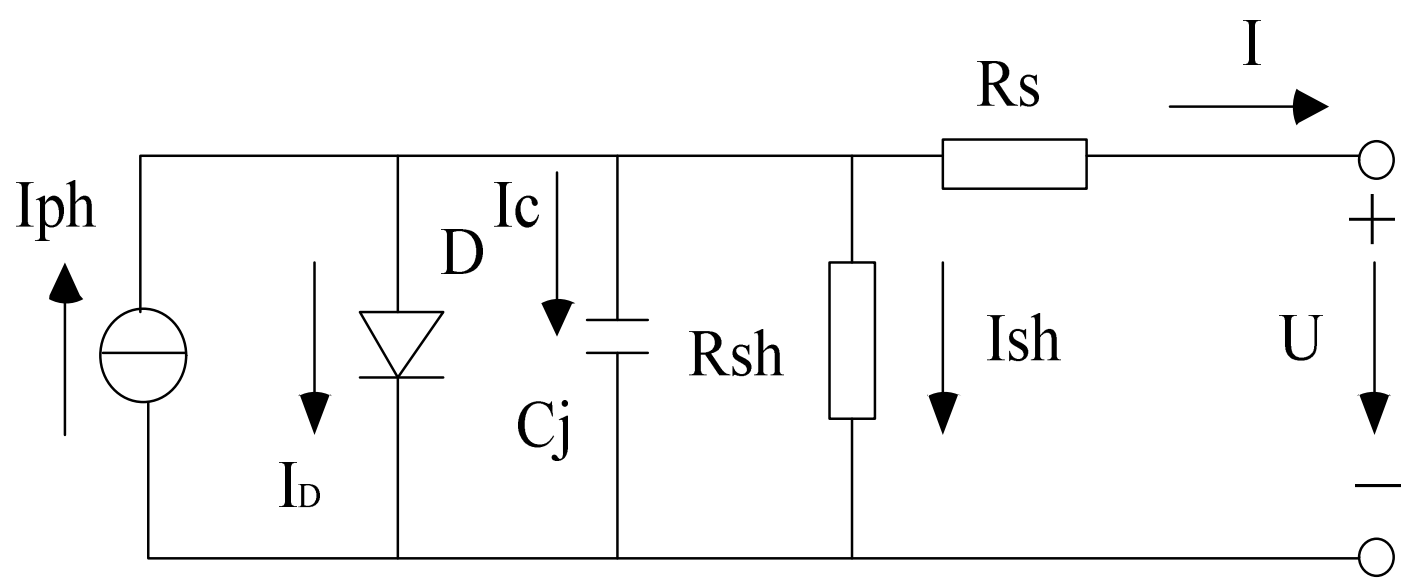

Fig. 1. electrical equivalent circuit of the model

Calculation of those five parameters is difficult because of the implicit form of the equation and the presence of the exponential terms. Although this equation can be solved with nonlinear optimization techniques, the accuracy of the extracted parameters depends on the type of algorithm, the objective function and the initial conditions [11-13]. In order to simplify the process, the parameters can be extracted by means of analytical methods.

The presence of $R_{s h}$ corresponds to the leakage current in the p-n junction. In practice, $R_{s h}$ is much lager than $U+I R_{s}$.Therefore $R_{s h}$ was ignored. Then equation (2) can be obtained:

$$
I=I_{p h}-I_{0}\left\{\exp \left[\frac{q\left(U+I R_{s}\right)}{A K T_{c}}\right]-1\right\}
$$

In equation (2), the exponential term is much larger than 1. Thus, Equation (2) can be further simplified as equation (3):

$$
I=I_{p h}-I_{0} \exp \left[\frac{q\left(U+I R_{s}\right)}{A K T_{c}}\right]
$$

Therefore, the model of the black silicon solar cell is described by equation (3). The model is a single diode model combined the diffusion current with recombination current, with the use of non-physical ideality factor A. Given a set of measured I-V data (provided by manufacturer or measured by $\mathrm{I}-\mathrm{V}$ tester), the parameter extraction problem for such a single diode model reduces to find four parameters: $\left\{A, R_{s}, I_{p h}, I_{0}\right\}$.

For a given PV module, in order to evaluate $A, R_{s}, I_{p h}, I_{0}$ in a particular environmental condition, a system of non-linear equations is generated by forcing to fit the I-V curve in four points. Three of the four equations of the system are determined imposing that the following points belong to the $\mathrm{I}-\mathrm{V}$ curve expressed by equation (3): open circuit point $\left(\mathrm{V}=\mathrm{V}_{\mathrm{oc}}, \mathrm{I}=0\right)$, short circuit point $\left(\mathrm{V}=0, \mathrm{I}=\mathrm{I}_{\mathrm{sc}}\right)$, maximum power point $\left(\mathrm{V}=\mathrm{V}_{\mathrm{m}}, \mathrm{I}=\mathrm{I}_{\mathrm{m}}\right)$. In these cases, equation (3) becomes: 


$$
\begin{aligned}
& 0=I_{p h}-I_{0} \exp \left[\frac{q U_{o c}}{A K T_{c}}\right] \\
& I_{s c}=I_{p h}-I_{0} \exp \left[\frac{q I_{s c} R_{s}}{A K T_{c}}\right] \\
& I_{m}=I_{p h}-I_{0} \exp \left[\frac{q\left(U_{m}+I_{m} R_{s}\right)}{A K T_{c}}\right]
\end{aligned}
$$

In equation (5), because the series resistance $R_{s}$ is relative smaller than the p-n junction resistance, the exponential term approximates to 0 . Then the equation becomes:

$$
I_{s c} \approx I_{p h}
$$

From equation (4) -(7), the expression for $A$ and $R s$ can be derived as

$$
\begin{aligned}
& A=\frac{q\left(U_{m}+I_{m} R_{s}-U_{o c}\right)}{K T_{c} \ln \left(1-I_{m} / I_{s c}\right)} \\
& R_{s}=\frac{\frac{U_{o c}}{\ln \left(I_{s c} / I_{m}\right)} \ln \left(\frac{I_{s c}-I_{m}}{I_{0}}\right)-U_{m}}{I_{m}}
\end{aligned}
$$

The photocurrent Iph can be influenced by the temperature and the irradiance as the Equation (10) described:

$$
I_{p h}=\left[I_{p h r e f}+K_{I}\left(T_{c}-T_{\text {cref }}\right)\right] \frac{S}{S_{\text {ref }}}
$$

Where $I_{p h r e f}$ is the $I_{p h}$ under the reference condition (e.g. at the standard temperature and irradiance), $S$ is the total solar irradiance on the solar cell, $S_{\text {ref }}$ is $S$ under the reference condition, $T_{c}$ is the ambient temperature, $T_{c r e f}$ is the reference temperature, $K_{I}$ is the temperature coefficient of short circuit current under the reference condition. In this study, assumed that $S_{\text {ref }}=1000 \mathrm{~W} / \mathrm{m}^{2}, K_{I}=0.0012 \mathrm{Isc}$, and $T_{\text {cref }}=$ $298 \mathrm{~K}$. $I_{\text {scref, }}$ which is the short current under reference condition, approximates the $I_{\text {phref. }}$.

The diode saturation current can derived from equation (11) and (12).

$$
\begin{aligned}
& I_{0}=I_{0 \text { ref }}\left(\frac{T_{c}}{T_{\text {cref }}}\right)^{3} \exp \left[\frac{q E_{g}}{A K}\left(\frac{1}{T_{\text {cref }}}-\frac{1}{T_{c}}\right)\right] \\
& E_{g}=E_{\text {gref }}\left[1-0.000267\left(T_{c}-T_{\text {cref }}\right)\right]
\end{aligned}
$$

Where $E g$ is the band gap energy, and $E_{\text {gref }}$ is reference band gap energy at $298 \mathrm{~K}$.

From the Equation (8)-(12), the parameter $A, I_{0}, R_{s}, I_{p h}$ can be derived. Plugging those 4 parameters to the equation (3), the electrical characteristic curves of the model of black silicon solar cell can be obtained. In this method, all the data can be taken from manufacturer or measured by solar cell tester. 


\section{Results and discussion}

In order to assess the accuracy of the present model, two kinds of black silicon solar cells provided by LDK Solar Co. Ltd. was selected as an example to illustrate the application of the method and the variation of the parameters for different irradiance conditions.

These solar cell types are respectively SY-012H-CC and SY-012-CC, which SY-012H-CC has porous shape substrate surface and SY-012-CC has comb-shape substrate surface.

The main electrical characteristics of the SY-012H-CC and the SY-012-CC under various irradiance at $298 \mathrm{~K}$ are respectively listed in Table 1 and 2, wherein Uoc, Isc, Um, Im under variable irradiance $(S)$ are provided by the manufacturer, $A, R s, I p h, I o$ of the model parameters are obtained by the present parameter estimation method.

Plugging the above-listed parameters data to the equation (3), the electrical characteristic models of SY-012H-CC and SY-012-CC under various irradiance are equation (13)-(18):

$$
\begin{aligned}
& I=8.249-1.1707 \times 10^{-8} \times \exp [33.38 \times(\mathrm{U}+0.003692 \mathrm{I})] \\
& I=6.599-1.1894 \times 10^{-8} \times \exp [33.37 \times(\mathrm{U}+0.003732 \mathrm{I})] \\
& I=4.949-1.0882 \times 10^{-8} \times \exp [33.36 \times(\mathrm{U}+0.003766 \mathrm{I})] \\
& I=8.19-9.6495 \times 10^{-9} \times \exp [33.33 \times(\mathrm{U}+0.003266 \mathrm{I})] \\
& I=6.552-1.0406 \times 10^{-8} \times \exp [33.29 \times(\mathrm{U}+0.003312 \mathrm{I})] \\
& I=4.914-1.0569 \times 10^{-8} \times \exp [33.27 \times(\mathrm{U}+0.003356 \mathrm{I})]
\end{aligned}
$$

Table 1 SY-012H-CC parameters at $\mathrm{T}=298 \mathrm{~K}$

\begin{tabular}{ccccccccc}
\hline $\mathrm{S}\left(\mathrm{W} / \mathrm{m}^{2}\right)$ & $\mathrm{Uoc}(\mathrm{V})$ & $\operatorname{Isc}(\mathrm{A})$ & $\mathrm{Um}(\mathrm{V})$ & $\operatorname{Im}(\mathrm{V})$ & $\mathrm{A}$ & $\operatorname{Rs}(\Omega)$ & $\operatorname{Iph}(\mathrm{A})$ & Io $(\mathrm{nA})$ \\
\hline 1000 & 0.6102 & 8.249 & 0.4941 & 7.7862 & 1.1653 & 0.003692 & 8.249 & 11.707 \\
800 & 0.6033 & 6.599 & 0.4948 & 6.1505 & 1.1658 & 0.003732 & 6.599 & 11.894 \\
600 & 0.5976 & 4.949 & 0.4960 & 4.5800 & 1.1663 & 0.003766 & 4.949 & 10.882 \\
\hline
\end{tabular}

Table 2 SY-012-CC parameters at $\mathrm{T}=298 \mathrm{~K}$

\begin{tabular}{ccccccccc}
\hline $\mathrm{S}\left(\mathrm{W} / \mathrm{m}^{2}\right)$ & $\mathrm{Uoc}(\mathrm{V})$ & $\operatorname{Isc}(\mathrm{A})$ & $\mathrm{Um}(\mathrm{V})$ & $\operatorname{Im}(\mathrm{V})$ & $\mathrm{A}$ & $\operatorname{Rs}(\Omega)$ & $\operatorname{Iph}(\mathrm{A})$ & Io $(\mathrm{nA})$ \\
\hline 1000 & 0.6172 & 8.190 & 0.5061 & 7.7075 & 1.1680 & 0.003266 & 8.190 & 9.6495 \\
800 & 0.6086 & 6.552 & 0.4991 & 6.1412 & 1.1687 & 0.003312 & 6.552 & 10.406 \\
600 & 0.5998 & 4.914 & 0.4978 & 4.5685 & 1.1693 & 0.003356 & 4.914 & 10.569 \\
\hline
\end{tabular}

From those equation (13)-(18), the I-V and P-V curves of the model can be obtained in Fig.2 Fig.5, which are the computed data curves and the measuring data curves of the SY -012H-CC and SY-012-CC cell. The results show that the computed curves fit well with the measuring curves in both of those two black silicon solar cells. This indicates that the present model matches well with black silicon solar cell and model parameter estimation method has high precision. 


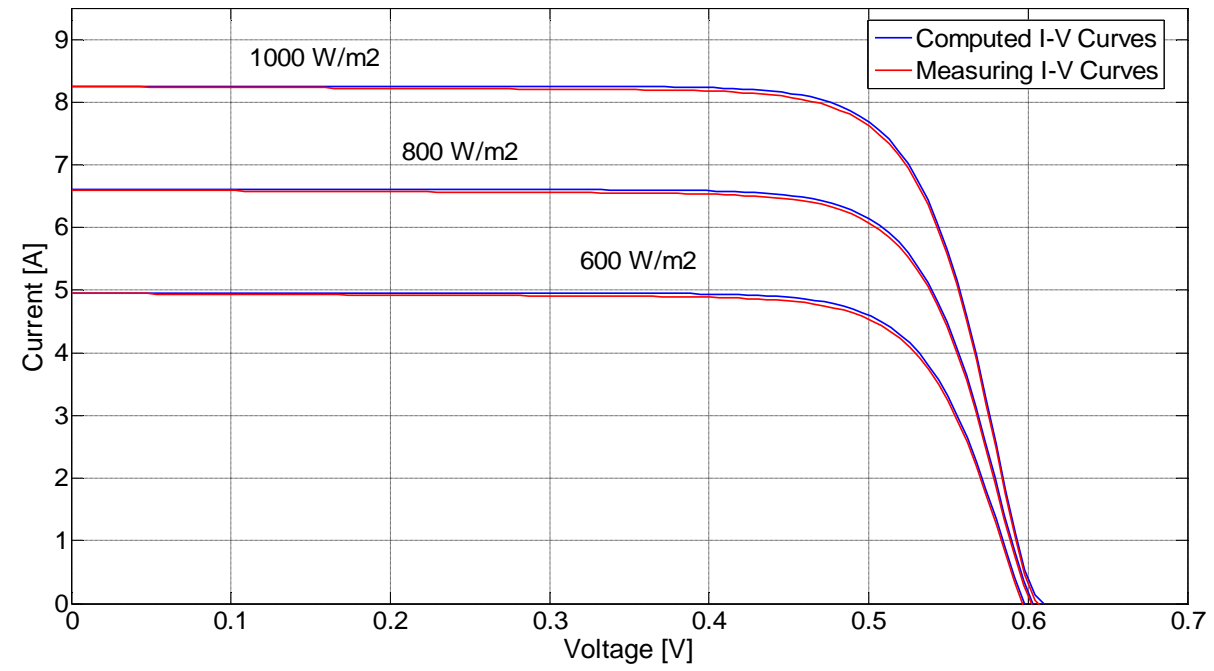

Fig. 2.the I-V curves of the SY-012H-CC solar cell

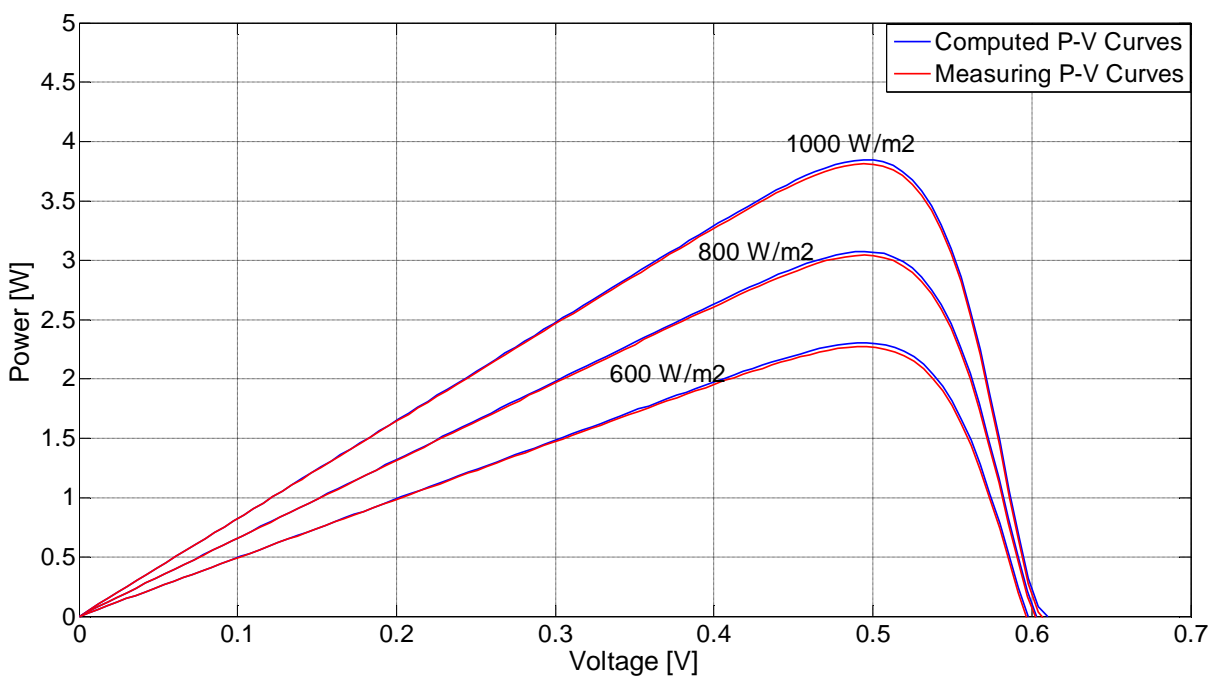

Fig.3. the P-V curves of the SY-012H-CC solar cell

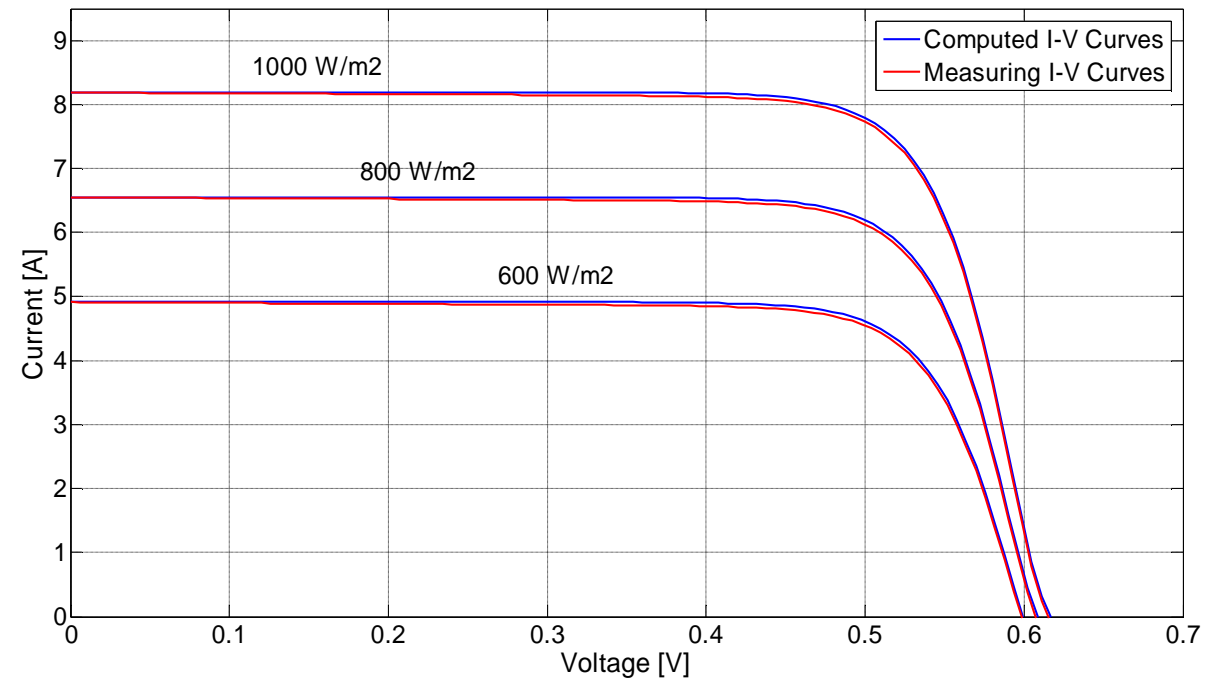

Fig.4. the I-V curves of the SY-012-CC solar cell 


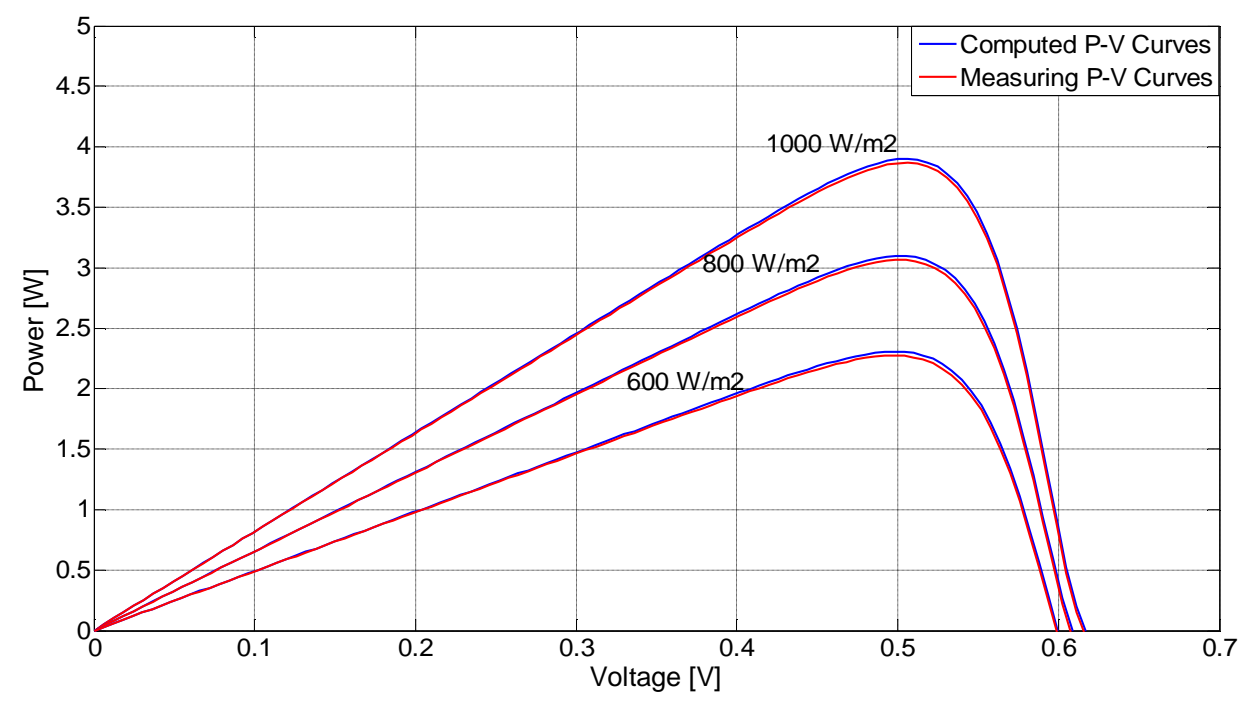

Fig.5. the P-V curves of the SY-012-CC solar cell

\section{Conclusions}

A simple lumped-parameter equivalent circuit model using single diode has been proposed in this work, to model the black silicon solar cells. The model contains linear and nonlinear components. Model parameters are extracted from the nonlinear equations by using some simplification and approximation methods. The comparison between the computed curves and measuring curves of two kinds of black silicon solar cells at various irradiance conditions has demonstrate that the model and model parameters estimation are effective and accurate.

\section{Acknowledgements}

This work was financially supported by the National Natural Science Foundation of China (Grant No. 61274059, 61474139).

\section{References}

[1] Saloux Etienne, Teyssedou Alberto, Sorin Mikhaïl: Solar Energy, 2011, 85: 713-722.

[2] Nema RK, Nema Savita, Agnihotri Gayatri: International Journal of Recent Trends in Engineering, 2009, 1(3): 151-156.

[3] Khazaei J, Miao Z, Piyasinghe L, Fan L: Electric Power Systems Research, 2015, 123: 85-91.

[4] Lo Brano V, Orioli A, Ciulla G, Di Gangi A: Solar Energy Materials and Solar Cells, 2010, 94(8): 1358-1370.

[5] Laudani A, Mancilla-David F, Riganti-Fulginei F, Salvini A: Solar Energy, 2013, 97:122-127.

[6] Orioli A, Di Gangi A: Applied Energy, 2013, 102:1160-1177.

[7] Savin H, Repo P, von Gastrow G, et al. Nature nanotechnology, 2015, 10(7): 624-628.

[8] Y. Xia, B. Liu, J. Liu, et al.: Solar Energy. 2011, 85: 1574-1578.

[9] Y. Xia, B. Liu, S. Zhong, and B. Chao: Journal of Electron Spectroscopy Related Phenomena. 2012, 184: 589-592.

[10] Shockley W. Electrons and holes in semiconductors. New York: Van Nostrand;1950. 
[11] Easwarakhanthan T, Bottin J, Bouhouch I, Boutrit C. Int J Solar Energy 1986;4:1-12.

[12] Chegaar M, Ouennoughi Z, Guechi F. Vacuum 2004;75:367-72

[13] Ortiz C et al. Solid-State Electron 1999;43:845-848. 